\title{
Evaluation of Chemical and Physical-morphological Factors as Potential Determinants of Biomphalaria pfeifferi (Krauss, 1848) Distribution
}

\author{
Jürg Utzinger ${ }^{*}+$, Charles Mayombana**, Konstanze Mez***, \\ Marcel Tanner*
}

\begin{abstract}
*Swiss Tropical Institute, Department of Public Health and Epidemiology, PO Box, CH-4002 Basel, Switzerland **Ifakara Centre, PO Box 53, Ifakara, Tanzania ***University of Zurich, Institute of Plant Biology/Microbiology, Zollikerstrasse 107, CH-8008 Zurich, Switzerland
\end{abstract}

This study was carried out in five sites along a small perennial river system in south-central Tanzania, which had been identified as the focus for transmission of intestinal schistosomiasis in the area. Malacological surveys preceding the study showed a focal distribution of Biomphalaria pfeifferi, intermediate host snail of Schistosoma mansoni, the snails being present in three sites but absent from the other two sites. The objective of this study was to evaluate to what extent chemical and/or physical-morphological factors determine the distribution of $\mathrm{B}$. pfeifferi between these five sites.

It was found that none of the chemical constituents in the waters examined were outside the tolerance range of B. pfeifferi snails. Moreover, the composition of water from B. pfeifferi-free sites was not different from that in those sites where snails occurred. Furthermore, none of the physical-morphological constituents seemed likely to be a determinant for the absence of $\mathrm{B}$. pfeifferi.

In view of these findings, and those of previous studies, it is concluded that the focal distribution of B. pfeifferi cannot be associated with a single environmental factor and is rather the result of more complex interactions of habitat factors.

Key words: Biomphalaria pfeifferi - physical-morphological factors - schistosomiasis - Tanzania - water chemistry

There is a considerable body of literature dealing with abiotic factors which can influence the presence, life cycles and distribution of snails of the family Planorbidae, many of which are intermediate hosts for schistosomiasis (for review see Appleton 1978).

In Tanzania, the two genera Bulinus and Biomphalaria of the African Planorbidae have been identified as intermediate hosts of Schistosoma haematobium and S. mansoni, respectively (Sturrock 1965). Those snails are known to tolerate a wide range of ecological conditions and they are termed 'euryok' (Hubendick 1958). The identification of a single key environmental factor that can determine the presence or absence of the snails is very difficult, and has so far proved disappointing (de Meillon et al. 1958, Schutte \& Frank 1964, Webbe 1962 and recently stated by Vercruysse et al.

Financial support was provided by UNDP/World Bank/ WHO/Special Programme for Research and Training in Tropical Diseases (TDR).

${ }^{+}$Corresponding author. Fax: +41-61-721.7951

Received 16 September 1996

Accepted 22 January 1997
1994). Appleton's review (1978) suggests that water temperature is the most important abiotic factor in lentic environments, whereas in lotic environments current velocity is the key factor.

Alves (1958) attempted to correlate the presence or absence of intermediate host snails with chemical water composition, and discovered that snail-free environments tended to have low calcium concentrations. Those findings were confirmed by Williams (1970a) who found in Rhodesia that $B$. pfeifferi was restricted to water with a minimum calcium concentration of $5 \mathrm{mg} / \mathrm{l} \mathrm{Ca}{ }^{2+}$. However, Bulinus globosus was found to be more tolerant of low calcium concentrations, both in field studies (Williams 1970a) and in experimental investigations (Williams 1970b). High magnesium/calcium ratios were found to have a negative impact on the egg production of $B$. pfeifferi (Harrison et al. 1966). Water with a sodium/calcium ratio exceeding 2.4 affected snail densities and $B$. pfeifferi was found very rarely in such conditions (Schutte \& Frank 1964). Polderman et al. (1985) found B. pfeifferi in waters with conductivities as low as $28 \mu \mathrm{S} \mathrm{cm}^{-1}$, but noticed its absence where conductivites were only 10 $12 \mu \mathrm{S} \mathrm{cm}^{-1}$. 
The starting point of this study was the observation that the distribution of $B$. pfeifferi within a small perennial river system was focal, the snails being present in the main river and in one branch above its confluence and one very small tributary but absent from all the other tributaries above the main confluence. The hypothesis was that either chemical or physical-morphological factors are determinants of snail habitats and explain their focal distribution.

\section{MATERIALS AND METHODS}

Study area - The study was carried out in the Mlali river system located in the Morogoro Rural district, Morogoro region of south-central Tanzania (Fig. 1). The rivers originate in the Uluguru mountains at altitudes between 1,000 and 1,500 m above sea level. After some $3-5 \mathrm{~km}$ the various tributaries join and become the river Mlali. This river flows through the villages of Kinyovi and Mlali. Further downstream the water is used for irrigation purposes, before the river drains into a large swamp. The transmission of human schistosomiasis in this area is high (Mayombana, personal communication) and the Mlali river was identified as the focus of disease transmission.

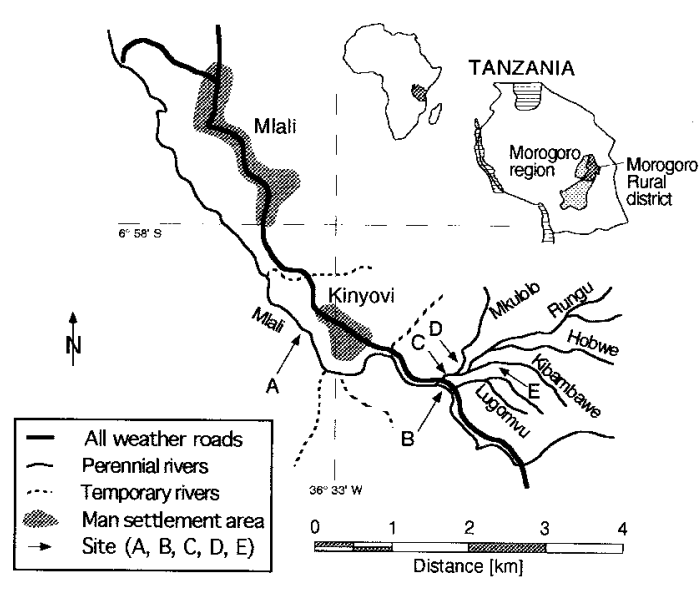

Fig. 1: map of the study area in Morogoro Rural district in the Morogoro region, south-central Tanzania, showing the five sites investigated.
Snail surveys and study sites chosen - Preceding the study, seven malacological surveys were carried out in the Mlali river between August 1993 and November 1994 in eight sites located downstream of site A. However, no B. pfeifferi snails were found. The following investigations focused on site A, where infected B. pfeifferi snails were found, however only during the dry season between December 1994 and February 1995 and between November 1995 and January 1996 (Table I). In the dry season, four additional sites (B, C, D and E) were surveyed, but no B. pfeifferi were found in sites C and D.

In early November 1995, the snail distribution was investigated at 17 different sites including site A and above. Snails were manually searched for always by the same two experienced field workers during a period of 10-15 min and the sites were classified into three classes: snails absent, snails present in low densities (1-10 snails), snails present in high densities (> 10 snails). Five sites were chosen for further investigations (Fig. 1).

Chemical water analysis - Water samples were taken three times during a period of low discharge in the dry season. All samples were collected in the middle of the river, $5 \mathrm{~cm}$ below the water surface, between 8:30 am and $10 \mathrm{am}$. Water temperatures and conductivities were measured directly in the field to the nearest $0.1^{\circ} \mathrm{C}$ and $1 \mu \mathrm{S} \mathrm{cm}^{-1}$, respectively, using a microprocessor pocket conductivity meter (model TertraCon 96, Germany). Water samples were brought to the laboratory and $\mathrm{pH}$ values were measured first. Immediately afterwards, the samples were filtered and analyzed for concentrations of ammonia, ferrous iron, phosphate and silica, using a Hitachi photospectrometer (Model 100-20, Japan).

The concentrations of metals $(\mathrm{Ag}, \mathrm{Al}, \mathrm{B}, \mathrm{Ca}$, $\mathrm{Cd}, \mathrm{Co}, \mathrm{Cu}, \mathrm{Cr}, \mathrm{Fe}, \mathrm{K}, \mathrm{Mg}, \mathrm{Mn}, \mathrm{Mo}, \mathrm{Na}, \mathrm{Ni}, \mathrm{Pb}$ and $\mathrm{Zn}$ ) were determined by Inductively Coupled Plasma-Atomic Emission Spectroscopy (ICP-AES, Spectro Analytical Instruments, Germany). Extracts were measured either directly or after dilution, with correction for background. Concentrations of the anions $\mathrm{Cl}^{-}, \mathrm{NO}_{3}{ }^{-}$, and $\mathrm{SO}_{4}{ }^{2-}$ were determined by High Precision Liquid Chromatography (HPLC) and conductivity detection (SuperSep, $100 \times 4.6 \mathrm{~mm}$,

TABLE I

Relative density of Biomphalaria pfeifferi in site A, as assessed by the number of snails scooped by two persons in $15 \mathrm{~min}$. Numbers in brackets indicate how many snails were infected

\begin{tabular}{lccccccccc}
\hline & \multicolumn{1}{c}{ Date of scooping in site A } \\
\cline { 2 - 9 } & 28.12 .94 & 13.1 .95 & 20.2 .95 & 1.4 .95 & 22.5 .95 & 10.6 .95 & 1.10 .95 & 28.11 .95 & 9.1 .96 \\
\hline B. pfeifferi & $62(30)$ & $45(3)$ & $22(9)$ & 0 & 0 & 0 & 0 & $118(30)$ & $180(72)$ \\
\hline
\end{tabular}


Metrohm, Switzerland) with phthalic acid as eluant $(0.3 \mathrm{mM}, 5 \%$ acetonitrile, $\mathrm{pH}=3.9)$.

In addition, on one day water temperatures and conductivities were measured in all sites at twohourly intervals between 8 am and $6 \mathrm{pm}$ and maximum values were recorded.

Physical-morphological habitat characteristics - Physical-morphological habitat characterization of the five sites was carried out according to Bovee (1982). In sites A, B and C, 10 transects and in sites D and E, 20 transects were set at right angles to the main current. Distances between adjacent transects had approximately the same length as the width of the river at the sites chosen. Along the transects, the width of the river was measured to the nearest $\mathrm{cm}$. The transects were divided into 11 (sites A, B and C) and 6 (sites D and E) equal sections, respectively. Points between adjacent sections were chosen as locations for physicalmorphological habitat assessment.

The water column depth was measured to the nearest $\mathrm{cm}$, using a calibrated stick, and the water velocity was measured to the nearest $\mathrm{cm} \mathrm{s}^{-1}$ with a current meter from Ott Ltd (Germany), fitted with a $2 \mathrm{~cm}$ propeller. The dominant substratum was assessed directly in the field in an area of $5 \times 5 \mathrm{~cm}$ beneath each point, according to a modified Wentworth scale using the following classification system: class 1: organic material, class 2: clay/silt (0.004-0.06 mm), class 3: sand $(0.07-2.0 \mathrm{~mm})$, class 4 : gravel (2.1-16 mm), class 5: pebbles (16.1-64 mm), class 6: cobbles (64.1-256 mm), class 7: boulders (> $256 \mathrm{~mm}$ ) and class 8: bedrock. It was found that with experience, reliable classifications could be made visually (Bain et al. 1985). In the few cases where there was doubt about the classifications, a sample of stones was measured with callipers.

At each site, the total area of the water body shaded and the coverage of submerged, emerged and floating vegetation (Madsen 1985) were estimated to the nearest $10 \%$ increments.

Statistical analysis - Analysis of variance techniques were used to determine the percentage of variance accounted for by variance within sites, and to calculate what proportion of this corresponded to the differences between sites with snails and those without.

\section{RESULTS}

Snail distribution - Four different snail species were found in the five study sites (Table II). B. globosus, the intermediate host of urinary schistosomiasis was found in sites $\mathrm{A}$ and $\mathrm{B}$, whereas B. pfeifferi occurred in sites A, B and E.

Water chemistry - The results of the chemical analyses of the water samples are summarized in Table III, which also shows separately the data for

\section{TABLE II}

Semi-quantitative snail survey carried out in November 1995. Snail classification as follows: snails absent (-), snails present in low densities (1-10 snails: + ), snails present in high densities (> 10 snails: ++$)$

\begin{tabular}{lccccc}
\hline Snail species & \multicolumn{5}{c}{ Site } \\
\cline { 2 - 6 } & A & B & C & D & E \\
\hline Biomphalaria pfeifferi & + & + & - & - & ++ \\
Bulinus globosus & + & + & - & - & - \\
Bulinus forskali & - & + & - & - & - \\
Melanoides tuberculata & + & ++ & + & - & ++ \\
\hline
\end{tabular}

sites where B. pfeifferi occurred or was absent. The samples were always taken in the morning, therefore the water temperatures were relatively low, ranging between $20.2^{\circ} \mathrm{C}$ (site $\mathrm{C}$ ) and $23.8^{\circ} \mathrm{C}$ (site A). However, considerable temperature variations were observed during a single day, when several measurements were taken and maximum temperatures were recorded either at $2 \mathrm{pm}$ or $4 \mathrm{pm}$, reaching $29.6,26.8,27.9,26.3$ and $25.2^{\circ} \mathrm{C}$ for sites A, B, C, D and E, respectively.

Conductivity values were high and varied from $183 \mu \mathrm{S} \mathrm{cm}^{-1}$ in site $\mathrm{E}$ to $382 \mu \mathrm{S} \mathrm{cm}^{-1}$ in site $\mathrm{D}$ which reflects that the amount of soluble salts in the parent rocks are high for the study area. The water conductivities showed only slight variations between $8 \mathrm{am}$ and $6 \mathrm{pm}$ and the differences were smaller than the variations between the different sites.

From one site to another, the maximum difference of $\mathrm{pH}$ values was 0.3 as assessed on individual surveys. Overall the $\mathrm{pH}$ values ranged between 6.8 and 8.6.

The dominant cations were either sodium or calcium with maximum concentrations of $34.78 \mathrm{mg} / \mathrm{l} \mathrm{Na}^{+}$in site $\mathrm{C}$ and $25.82 \mathrm{mg} / \mathrm{l} \mathrm{Ca}^{+}$in site $\mathrm{D}$, respectively. The ratio between magnesium and calcium was fairly constant and varied from 0.66 to 0.80 . The sodium/calcium ratio was also relatively constant with the highest ratio of 1.38 measured at site D. Concentrations of Ag, Al, B, $\mathrm{Cd}, \mathrm{Co}, \mathrm{Cu}, \mathrm{Cr}, \mathrm{Ni}, \mathrm{Pb}, \mathrm{Zn}$ were all below the limits of detection and oscillations were within background noise.

The dominant anion was silica, and the high concentrations indicate good mobility in the soil. Low sulphate and phosphorus concentrations were measured in all five sites. Nitrates were absent except during the second survey in site D and the third survey in site $\mathrm{C}$, when concentrations of 20.62 and $0.18 \mathrm{mg} / \mathrm{NO}_{3}{ }^{-}$were recorded. Concentrations of ammonia were less than $0.1 \mathrm{mg} / \mathrm{l}$ in all sites. 
In summary, for all the chemicals investigated, the variance within and between the five sites was much larger than the variance between the sites where B. pfeifferi occurred or was absent (Table III).

Physical-morphological habitat characteristics -The physical-morphological characteristics of the five sites are given in Table IV. The mean river widths, the mean water depths and the mean water velocities measured in the $B$. pfeifferi-free habitats (sites $C$ and $D$ ) were in the range between those where snails occurred (sites A, B and E). Therefore these three physical-morphological constituents are not considered to determine the presence or absence of $B$. pfeifferi. The highest mean water velocities, $24.6 \mathrm{~cm} \mathrm{~s}^{-1}$ and $20.4 \mathrm{~cm}$ $\mathrm{s}^{-1}$ were measured at sites B and E, respectively, where B. pfeifferi occurred.

Substratum composition in the five sites varied a lot (Fig. 2). The finest substratum fraction was observed in site $\mathrm{E}$, with organic material as the median dominant substratum class. The coarsest substratum fraction was found in site $\mathrm{C}$, which was a $B$. pfeifferi-free habitat.

The dominant type of aquatic vegetation was emergent vegetation, but it covered an area of only $10-20 \%$ in sites A, B, C and D, though in site E, an estimated area of $60 \%$ was covered. The total area

TABLE III

Summary of chemical analyses of water samples from all five sites at three different dates in November 1995. Mean and standard deviation (S.D.) for all five sites and the sites where Biomphalaria pfeifferi occurred or was absent and percentages of variance accounted for by variance within and between the sites

\begin{tabular}{|c|c|c|c|c|c|c|}
\hline \multirow{2}{*}{$\begin{array}{l}\text { Factors } \\
\text { analyzed }\end{array}$} & \multicolumn{3}{|c|}{ Mean (S.D.) } & \multicolumn{3}{|c|}{ Variance (\%) } \\
\hline & All sites & $\begin{array}{l}\text { Sites with } \\
\text { B. pfeifferi }\end{array}$ & $\begin{array}{l}\text { Sites without } \\
\text { B. pfeifferi }\end{array}$ & $\begin{array}{l}\text { Within } \\
\text { sites }\end{array}$ & $\begin{array}{l}\text { Between } \\
\text { sites }\end{array}$ & $\begin{array}{l}\text { Between } \\
\text { sites, } \\
\text { snails: +/- }\end{array}$ \\
\hline \multicolumn{7}{|l|}{ Cations (mg/l) } \\
\hline $\mathrm{Ca}^{2+}$ & $18.71(4.90)$ & $18.20(4.57)$ & $19.61(6.05)$ & 10.41 & 89.59 & 2.11 \\
\hline $\mathrm{K}^{+}$ & $1.40(1.10)$ & $1.57(1.33)$ & $1.15(0.45)$ & 72.74 & 27.26 & 3.97 \\
\hline $\mathrm{Mg}^{2+}$ & $13.42(3.91)$ & $12.75(3.21)$ & $14.60(5.25)$ & 4.68 & 95.32 & 5.64 \\
\hline $\mathrm{Mo}^{2+}$ & $5.36(1.58)$ & $5.18(1.41)$ & $5.60(1.94)$ & 7.84 & 92.16 & 1.83 \\
\hline $\mathrm{Na}^{+}$ & $19.25(7.80)$ & $16.74(3.48)$ & $23.63(11.76)$ & 3.51 & 96.49 & 19.85 \\
\hline $\mathrm{Fe}(\mathrm{III})$ & $0.25(0.16)$ & $0.24(0.18)$ & $0.25(0.12)$ & 45.29 & 54.71 & 0.13 \\
\hline \multicolumn{7}{|l|}{ Anions (mg/l) } \\
\hline $\mathrm{Cl}^{-}$ & $2.84(0.76)$ & $2.95(0.63)$ & $2.82(1.00)$ & 27.59 & 72.41 & 0.68 \\
\hline $\mathrm{NO}_{3}^{-}$ & $1.49(5.51)$ & $0(0)$ & $3.47(8.40)$ & 71.52 & 28.48 & 10.91 \\
\hline $\mathrm{P}^{3}$ & $0.51(0.50)$ & $0.41(0.37)$ & $0.68(0.63)$ & 86.18 & 13.82 & 7.93 \\
\hline $\mathrm{SO}_{4}^{2-}$ & $1.36(0.99)$ & $1.62(1.24)$ & $1.14(0.34)$ & 2.93 & 97.07 & 6.17 \\
\hline $\mathrm{Si}$ & $19.60(5.34)$ & $19.33(5.39)$ & $20.00(6.06)$ & 70.59 & 29.41 & 0.42 \\
\hline $\mathrm{pH}$ & $7.66(0.64)$ & $7.78(0.71)$ & $7.63(0.63)$ & 98.10 & 1.90 & 1.22 \\
\hline Temperature $\left({ }^{\circ} \mathrm{C}\right)$ & $21.9(1.0)$ & $22.2(1.1)$ & $21.8(1.0)$ & 68.70 & 31.30 & 3.92 \\
\hline Conductivity $\left(\mu \mathrm{S} \mathrm{cm}^{-1}\right)$ & $265(72)$ & $252(48)$ & $288(94)$ & 3.39 & 96.61 & 6.79 \\
\hline
\end{tabular}

TABLE IV

Physical-morphological habitat characteristics for the five sites

\begin{tabular}{|c|c|c|c|c|c|}
\hline \multirow{2}{*}{$\begin{array}{l}\text { Physical-morphological } \\
\text { parameters analyzed }\end{array}$} & \multicolumn{5}{|c|}{ Site } \\
\hline & $\mathrm{A}^{a}$ & $\mathrm{~B}^{a}$ & $\mathrm{C}$ & $\mathrm{D}$ & $\mathrm{E}^{a}$ \\
\hline Mean river width (S.D.) [m] & $6.29(1.23)$ & $5.39(1.29)$ & $5.54(1.76)$ & $1.06(0.40)$ & $0.40(0.16)$ \\
\hline Mean water depth (S.D.) $[\mathrm{cm}]$ & $12.6(10.7)$ & $7.4(6.2)$ & $12.7(31.7)$ & $3.6(4.2)$ & $3.6(1.6)$ \\
\hline Mean water velocity (S.D.) $\left[\mathrm{cm} \mathrm{s}^{-1}\right]$ & $13.9(10.6)$ & $24.6(21.7)$ & $14.2(12.5)$ & $10.4(10.4)$ & $20.4(8.4)$ \\
\hline Median dominant substratum & sand & gravel & pebbles & sand & org. material \\
\hline Area shaded $[\%]$ & 30 & 30 & 20 & 30 & 80 \\
\hline Submerged vegetation [\%] & 0 & 0 & 0 & 0 & 20 \\
\hline Emergent vegetation [\%] & 20 & 20 & 20 & 10 & 60 \\
\hline Floating vegetation $[\%]$ & 0 & 0 & 0 & 0 & 10 \\
\hline
\end{tabular}

$a$ : presence of Biomphalaria pfeifferi snails; S.D.: standard deviation 


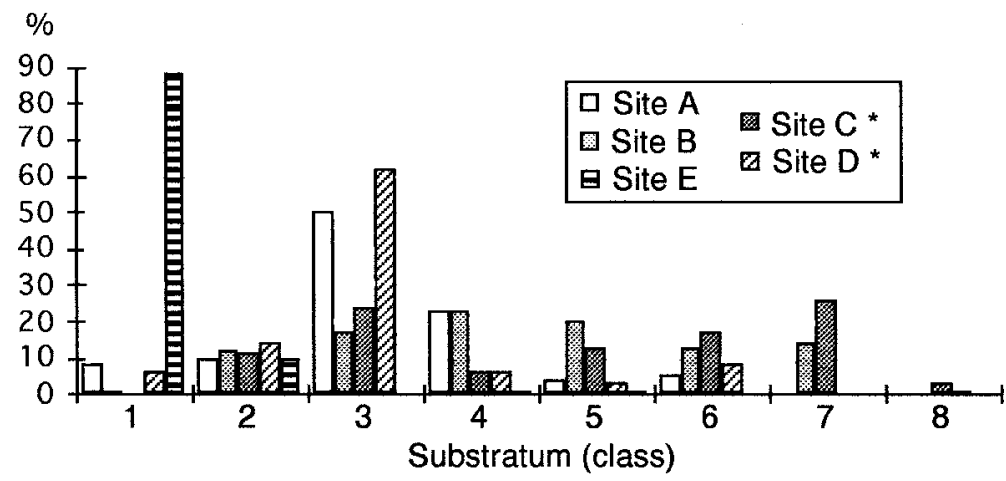

Fig. 2: substratum composition at all the five sites investigated. Substratum classification as follows 1: organic material, 2: clay/silt (0.004-0.06 mm), 3: sand (0.07-2.0 mm), 4: gravel (2.1-16 mm), 5: pebbles (16.1-64 mm), 6: cobbles (64.1-256 mm), 7: boulders (> 256 mm), 8: bedrock. Asterisks (*) indicate Biomphalaria pfeifferi-free habitats.

shaded was $20-30 \%$ in site $\mathrm{A}, \mathrm{B}, \mathrm{C}$ and $\mathrm{D}$, whereas $80 \%$ of the area was shaded in site $\mathrm{E}$.

\section{DISCUSSION}

Thomas and Tait (1984) reported the absence of intermediate host snails of schistosomiasis in a stream above its confluence with the main stream, in which snails occurred. However, no evidence of differences either in physical-morphological or in chemical water conditions had been found which could explain the distinct distribution of the snails. Several other attempts were undertaken to correlate the absence of snails with a single environmental factor, but it proved to be difficult (de Meillon et al. 1958, Webbe 1962, Schutte \& Frank 1964).

On the other hand it is well acknowledged that the distribution of schistosomiasis is focal (Sturrock 1993), and that transmission only takes place in areas where intermediate host snails are present and where the human population is frequently in contact with infected water. The precise distribution of snails is therefore of considerable potential importance for human health, and an understanding of the factors regulating snail distribution could be valuable for control purposes.

The investigation by Thomas and Tait (1984) for B. pfeifferi and a study by Baptista and Jurberg (1993) for B. tenagophila focused on the micro distribution of snails. In the latter study, snail distribution was investigated within an irrigation system and the sites where B. tenagophila occurred contained a significantly higher amount of organic matter.

The distribution of $B$. pfeifferi in the river system studied here was also found to be focal. However, in the present study, none of the individual chemical constituents in the water samples examined exceeded the tolerance range for $B$. pfeifferi snails: water temperatures measured in the morning as well as the maximum temperatures in the afternoon lay within the favourable range (Appleton 1978), water conductivites were above the critical value (Polderman et al. 1985) and calcium concentrations were at least $2 \frac{1}{2}$ times higher than the minimum value of $5 \mathrm{mg} / \mathrm{l} \mathrm{Ca}^{2+}$ (Williams 1970a, b). The magnesium/calcium ratios were low and never exceeded 0.8 , and were therefore unlikely to have had a negative impact on the egg production of B. pfeifferi (Harrison et al. 1966). The highest sodium/calcium ratio was recorded at site D but its value, 1.38, was below the critical value of 2.4 (Schutte \& Frank 1964).

Moreover, water composition in the two B. pfeifferi-free sites was in the range found in sites where snails were present. The only exception was that nitrates were detected in sites $C$ and $\mathrm{D}$, the $B$. pfeifferi-free habitats, but they were found only once in each of those two sites, which makes any interpretation rather difficult.

Although dissolved oxygen has been considered as an additional chemical determinant for the absence of B. pfeifferi snails (Thomas \& Tait 1984), it was not investigated in the present study. However, as stated by Donnelly and Appleton (1985), it is unlikely to be a limiting factor in areas like that of the present study, where there is only a moderate density of aquatic vegetation.

For physical-morphological constituents, the same conclusions must be drawn as for the water chemistry. None of the individual parameters was considered to determine the absence of $B$. pfeifferi snails. Current velocity, which might delineate the key factor in lotic environments (Appleton 1978) was found to be relatively high in sites B and E. In both those sites B. pfeifferi occurred, and therefore this parameter was not considered as a deter- 
mining factor for snail distribution. This might be explained by the fact that the mean velocities measured in those sites were still below the critical value of $30 \mathrm{~cm} \mathrm{~s}^{-1}$.

Shade has recently been considered as a means of ecological control of B. pfeifferi (Loreau \& Baluku 1991), but this possibility could not be confirmed, since $B$. pfeifferi occurred in site $\mathrm{E}$, where as much as $80 \%$ of the area was shaded.

Little is known about predators and parasites of schistosome intermediate host snails as potential agents for their biological control; however, other competitive snail species, such as Melanoides tuberculata, have been considered to be promising candidates (Madsen 1990). However, in Senegal $M$. tuberculata is positively correlated with B. pfeifferi (Madsen et al. 1988). In the present study, B. pfeifferi was found in sites A, B and E, and all those sites were inhabited by $M$. tuberculata.

Concluding, it needs to be emphasised that it was not possible to identify any individual factoreither chemical or physical-morphological - which explains the focal distribution of $B$. pfeifferi. The study provides further evidence that the distribution of these snails is a result of more complex interactions of different habitat factors, as had already been shown in previous studies.

\section{ACKNOWLEDGEMENTS}

To A Mtandanguo and S Mtandanguo from the Ifakara Centre for assistance in the field. To Prof. LR Kurvijila from the Sokoine University of Agriculture for providing laboratory facilities. To JM Jenkins for critical reading and helpful suggestions and to Dr T Smith and I Mueller for statistical support.

\section{REFERENCES}

Alves W 1958. Chemical constituents of surface water in Southern Rhodesia, with special reference to the molluscan vectors of bilharziasis. Bull WHO 18: 1071.

Appleton CC 1978. Review of literature on abiotic factors influencing the distribution and life cycles of bilharziasis intermediate host snails. Malacol Rev 11: $1-25$.

Bain MB, Finn JT, Booke HE 1985. Quantifying stream substrate for habitat analysis studies. $N$ Am J Fish Manage 5: 499-500.

Baptista DF, Jurberg P 1993. Factors conditioning the habitat and the density of Biomphalaria tenagophila (Orbigny, 1835) in an isolated schistosomiasis focus in Rio de Janeiro city. Mem Inst Oswaldo Cruz 88: 457464.

Bovee KD 1982. A guide to stream habitat analysis using the Instream Flow Incremental Methodology. FWS/OBS-82/26. U.S. Fish and Wildlife Service, Fort Collins, Colorado, 248 pp. de Meillon B, Frank GH, Allanson BR 1958. Some aspects of snail ecology in South Africa. Bull WHO 18: 771-783.

Donnelly FA, Appleton CC 1985. Observations on the field transmission dynamics of Schistosoma mansoni and S. mattheei in southern Natal, South Africa. Parasitology 91: 281-290.

Harrison AD, Nduku W, Hooper ASC 1966. The effects of a high magnesium-to-calcium ratio on the egg-laying rate of an aquatic planorbid snail, Biomphalaria pfeifferi. Ann Trop Med Parasitol 60: 212-214.

Hubendick B 1958. Factors conditioning the habitat of freshwater snails. Bull WHO 18: 1072-1080.

Loreau M, Baluku B 1991. Shade as a means of ecological control of Biomphalaria pfeifferi. Ann Trop Med Parasitol 85: 443-446.

Madsen H 1985. Ecology and control of African freshwater pulmonate snails. Part I: Life cycle and methodology. Danish Bilharziasis Laboratory, Charlottenlund, $36 \mathrm{pp}$.

Madsen H 1990. Biological methods for the control of freshwater snails. Parasitol Today 6: 237-241.

Madsen H, Daffalla AA, Karoum KO, Frandsen F 1988. Distribution of freshwater snails in irrigation schemes in the Sudan. J Appl Ecol 25: 853-866.

Polderman AM, Kayiteshonga M, Manshande JP, Gryseels B, Van Schayk O 1985. Historical, geological and ecological aspects of transmission of intestinal schistosomiasis in Maniema, Kivu Province, Zaire. Ann Soc belge Méd trop 65: 251-261.

Schutte CHJ, Frank GH 1964. Observations on the distribution of freshwater mollusca and chemistry of the natural waters in the south-eastern Transvaal and adjacent northern Swaziland. Bull WHO 30: 389-400.

Sturrock RF 1965. The development of irrigation and its influence on the transmission of bilharziasis in Tanganyika. Bull WHO 32: 225-236.

Sturrock RF 1993. The intermediate hosts and host-parasite relationships, p. 33-85. In P Jordan, G Webbe, RF Sturrock (eds), Human schistosomiasis. CAB International, Wallingford.

Thomas JD, Tait AI 1984. Control of the snail hosts of schistosomiasis by environmental manipulation: a field and laboratory appraisal in the Ibadan area, Nigeria. Phil Trans, Ser B 305: 201-253.

Vercruysse J, Southgate VR, Rollinson D, De Clercq D, Sacko M, De Bont J, Mungomba LM 1994. Studies on transmission and schistosome interactions in Senegal, Mali and Zambia. Trop geogr Med 46: 220226.

Webbe G 1962. The transmission of Schistosoma haematobium in an area of Lake province, Tanganyika. Bull WHO 27: 59-85.

Williams NV 1970a. Studies on aquatic pulmonate snails in Central Africa. I: Field distribution in relation to water chemistry. Malacologia 10: 153-164.

Williams NV 1970b. Studies on aquatic pulmonate snails in Central Africa. II: Experimental investigation of field distribution patterns. Malacologia 10: 165-180. 